\title{
NOVOS DADOS SOBRE MINERAIS URANÍFEROS SECUNDÁRIOS DO PEGMATITO DE PERUS, MUNICÍPIO DE SÃO PAULO*
}

\author{
DANIEL ATENCIO**, REINER NEUMANN**, J. AIDO CARMO JR.**, EDNA H. MISHTMA**
}

Os minerais uraníferos do pegmatite de Perus (Noroeste do Município de São Paulo), que ocorrem como preenchimento de fraturas, já foram objeto de alguns estudos mineralógicos, entre os quais destaca-se o de Camargo (Tese de Cátedra, Fac. FU. Ciên. Letras USP, 216 p., 1965). Os minerais identificados por esse autor foram autunita, meta-autunita, "hidrogênio autunita", fosfuranilita, "mineral X", torbernita, meta-torbenita, uranofânio, beta-uranofânio e opala uranífera.

A abertura de novas frentes de exploração permitiu a coleta de quantidade adicional de minerais, possibilitando a obtenção de novos dados.

O mineral "hidrogênio autunita" foi formalmente descrito e rebatizado como chernikovita (Atencio, Mineral Rec. 19(4):249-252,1988), descartando-se o nome anterior.

Novas amostras do "mineral X" permitiram verificar sua identidade com furcalita. Deliens \& Piret (Buli. Mineral. 101:356-358, 1978) descreveram em Bergen an der Trieb, Alemanha Federal, um mineral supostamente novo, ao qual denominaram furcalita. Tendo em vista que: a. a furcalita de Perus corresponde, de fato, à primeira ocorrência mundial; $b$. seus cristais são os mais bem formados; c. a descrição da furcalita permanece incompleta; e d. seu estudo estrutural (Piret \& Declercq, Acta Cryst. B34:1677-1679, 1978) não atingiu bom refinamento, pareceu oportuno o desenvolvimento de estudos completos. A furcalita de Perus apresenta-se na forma de agregados fibrorradiados de cristais euedrais, tabulares segundo [010] e alongados segundo [001], atingindo até $5 \mathrm{~mm}$ de comprimento. É biaxial negativa, $\alpha 1,677(2), \beta=1,732$, -y $=1,766(2), 2 \mathrm{~V}_{\mathrm{X}}$ obs. $=75^{\circ}, 2 \mathrm{~V}_{\mathrm{X}}$ cale. $=74^{\circ}, \mathrm{X}=\mathrm{b}, \mathrm{Y}=\mathrm{a}$, $\mathrm{Z}=\mathrm{c}$, pleocroísmo $\mathrm{X}=$ amarelo-claro, $\mathrm{Y}=$ amarelo, $\mathrm{Z}=$ amarelo-ouro. $\mathrm{O}$ grupo espacial é Pbca, $\mathrm{Z}=8, \mathrm{a}_{\mathrm{O}}=17,415(2)$, $\mathrm{b}_{\mathrm{O}}=16,035(3), \mathrm{c}_{0}=13,598 \AA$. A fórmula proposta por Deliens \& Piret (1978) é $\mathrm{Ca}_{2},\left(\mathrm{UO}_{2}\right)_{3}\left(\mathrm{PO}_{4}\right)_{2}(\mathrm{OH})_{4} 4 \mathrm{H}_{2} \mathrm{O}$, mas estudos da estrutura em andamento indicam a presença de um átomo adicional de oxigênio. Os dados completos da furcalita de Perus serão objetos de publicação posterior.

A existência de um fosfato de urânio e bário foi agora registrada em Perus. Seus dados de difração de raios X e EDS coincidem com os da meta-uranocircita, mas os índices de refração são superiores aos daquele mineral. Este mineral de Perus apresenta-se com boa a ótima clivagem basal, mas com desenvolvimento morfológiço maior, em alguns cristais, perpendicular à mesma clivagem. Apresenta, portanto, tendência prismática e não placóide basal. E biaxial, com a bissetriz aguda aproximadamente perpendicular à clivagem, $2 \mathrm{~V}_{\mathrm{X}}=20$ $30, \alpha=1,639, \beta=\gamma=1,641$. A cor é verde-clara, com pleocroísmo inexistente a muito fraco. Apresenta-se cores de interferência levemente anômalas. Estudos adicionais estão em andamento.

Cerca de 450 amostras de minerais secundários foram obtidas em Perus e classificadas em 153 categorias, de acordo com a combinação de características macroscópicas (cor, hábito, cor de fluorescência sob luz ultravioleta de ondas curtas e longas). Seu estudo permitirá ampliar os conhecimentos sobre a ocorrência.

Agradecimentos especiais a J.M.V. Coutinho, Karin Mangold, A.C. Kaminski, R. Hypolito e CNPq (Proc. 803022/87.5).

\footnotetext{
* Resumo do trabalho apresentado no I Simpósio Regional de Geologia do Sudeste, publicado no Boletim de Resumos com falhas de impressão ** Instituto de Geociências, Universidade de São Paulo, Caixa Postal 20899, CEP 01498, São Paulo, SP
} 